\title{
Hypertension and cardiac failure
}

\author{
J. M. FowLER
}

THERE are three major causes of death in hypertension; uraemia, cerebrovascular disease and heart disease. It is tecoming apparent that although treatment reduces the mortality from renal failure and strokes, the survivors apparently become increasingly prone to die as a consequence of myocardial infarction and heart disease (Breckenridge, Dollery \& Parry, 1970). In the developed world hypertensive heart disease is commonly complicated by coronary artery disease, so that it is difficult to distinguish between the effects of high blood pressure alone, and those of complicating ischaemia. This is not so amongst the indigenous rural peoples of tropical Africa, where significant coronary artery disease is an extreme rarity. Hypertension, on the other hand, is common in these peoples, and it should therefore be possible to examine the effect of hypertension on the heart unotscured by complicating coronary artery disease.

Much of the morbidity of hypertension in Africa is a consequence of uraemia, as much of the hypertension is renal in origin. Because of the low intake of protein in the normal diet, renal failure may present not as a consequence of the accumulation of nitrogenous substances, but as fluid and electrolyte disturbances.

Thus renal failure, which is common, may mimic cardiac failure, and the pulmonary oedema, triple rhythm and high venous pressure may be attributed in error to the effect of hypertension on the heart, and not correctly to the renal damage which causes both the hypertension and circulatory overload. Our experience would suggest that cardiac failure in African hypertensives is rare in the presence of normal renal function, provided there is no anaemia or valvular heart disease, both of which may complicate hypertension in Africa.

Is this conclusion surprising? In a study of heart failure in hypertensives in London, Mickerson (1963) reached broadly the same conclusion. He found, in a series of 445 patients with high blood pressure and heart failure, that a cause for heart failure other than hypertension could be found in all but twelve.

We may also use as analogies other situations where the ventricular muscle has to work against an enormously increased pressure load, and note that although massive hypertrophy is common, heart failure is rare. Thus, in uncomplicated moderate pulmonary stenosis the right ventricular mass, which is ill-adapted to dealing with a pressure load, has to work against a resting pressure of $100-150 \mathrm{mmHg}$. Angina, syncope and fatigue on effort are all more common than is the development of failure in the adult (Tinker et al., 1965). Left ventricular failure is similarly rare in uncomplicated cases of coarctation (Newman, 1948) and congenital aortic stenosis under the age of 40 years, and when it occurs some new complication is usually responsible.

Thus, the evidence from Europe, from analogies drawn from intraventricular hypertension in young people and from tropical Africa would all suggest that failure is rarely the result of simply dealing with a prolonged elevated pressure load, unless this situation is complicated by another source of strain.

A further source of cardiac embarrassment which may apparently complicate hypertension and lead to the development of failure is an arrhythmia. Rothstadt found atrial fibrillation to be present in $8 \%$ of unselected hypertensives (Rothstadt, 1938). In our series of ninety-one African patients with severe hypertension, whose age structure is shown in Table 1, there was no case of atrial fibrillation. Left atrial hypertrophy, however, was common.

TABLE 1.

\begin{tabular}{lcc}
\hline Age & Male & Female \\
\hline $20-39$ & 23 & 27 \\
$40-59$ & 18 & 14 \\
$60+$ & 8 & 1 \\
Total & 49 & 42 \\
\hline
\end{tabular}

Another striking finding in the ECGs was the comparative rarity of left anterior hemiblock giving a frontal plane axis of $-30^{\circ}$ or beyond. Eighty-two of the ninety-one patients had an axis more positive than $0^{\circ}$. Four patients, all male, had an axis between $-15^{\circ}$ and $-30^{\circ}$, and four had an axis between $0^{\circ}$ and $-15^{\circ}$.

Mazzoleni et al. (1964) found left axis deviation to be present in 'only' $35 \%$ of cases of pure left ventricular hypertrophy and stressed its infrequency compared with previous reports.

In our African series, gross voltage changes and gross ST-T changes were the rule. We have, therefore, tentatively concluded that left anterior hemiblock and atrial fibrillation which commonly occur in hypertension in the Western world do so because 
of the undue susceptibility of the hypertensive to coronary artery disease, of which these ECG findings are a manifestation.

\section{References}

Breckenridge, A., Dollery, C.T. \& Parry, E.H.O. (1970)

Prognosis of treated hypertension. Quarterly Journal of Medicine, 39, 411.

Mazzoleni, A., Wolff, R., Wolff, L. \& Reiner, L. (1964) Correlation between component cardiac weights and electrocardiographic pattern in 185 cases. Circulation, 30, 808.

Mickerson, J.N. (1963) Heart failure in hypertensive patients. American Heart Journal, 65, 267.

Newman, M. (1948) Coarctation of the aorta. British Heart Journal, 10, 150.

RothstadT, L.E. (1938) The effect of auricular fibrillation on the course of hypertension. Medical Journal of Australia, $1,813$.

Tinker, J., Howitt, G., Markman, P. \& Wade, E.G. (1965) The natural history of isolated pulmonary stenosis. British Heart Journal, 26, 380.

\section{Discussion}

DR SHAPER: Do the African hypertensive subjects attending the out-patient clinic in Uganda have angina, or chest pain similar to angina?

DR Fowler: No, there is no complaint at all of angina.

DR Dickinson: I would say in general from my experience of treating hypertensives in this country, that they should not die of heart failure. All my hypertensives die of acute myocardial infarction or acute cerebral infarcts. However, I would agree that untreated, a high proportion of hypertensives in this country would die of heart failure. This has been well documented.

DR OAKLEY: I would suggest that the reason that very few hypertensives die of heart failure is that as soon as they develop heart failure they are called cardiomyopathies and are referred to other clinics!

DR Dickinson: Oh no they don't! I intensify their diuretic regimen and hang on to them! 